\title{
Improving intravenous fluid therapy in children with gastroenteritis
}

\author{
Michael L. Moritz • Juan Carlos Ayus
}

Received: 25 February 2010 /Revised: 1 March 2010 / Accepted: 2 March 2010 /Published online: 23 March 2010

(C) IPNA 2010

\begin{abstract}
Gastroenteritis is one of the most common medical conditions seen by pediatricians. The standard approach to intravenous fluid therapy for these children has been to administer a $0.9 \%$ sodium chloride $(\mathrm{NaCl})$ bolus followed by a hypotonic solution ranging from $0.2-0.45 \% \mathrm{NaCl}$ to replace the remaining deficit plus maintenance. We have questioned the safety of this approach as there have been reports of death or permanent neurologic impairment from hyponatremic encephalopathy. Hanna and Saberi (Pediatr Nephrol. doi:10.1007/s00467-009-1428-y) found the incidence of hospital-acquired hyponatremia (sodium $<135 \mathrm{mEq} / \mathrm{L}$ ) to be $18.5 \%$ for patients presenting with isonatremic dehydration from gastroenteritis. This confirms that the current approach of using hypotonic fluids results in a high incidence of hyponatremia. Hypotonic fluids are not appropriate for rehydration in patients with gastroenteritis as it is a state of arginine vasopressin (AVP) excess due to both hemodynamic stimuli from volume depletion and non-hemodynamic stimuli such as nausea and vomiting. Free water will be retained until the volume deficit is corrected and the hemodynamic stimulus for AVP production abates. A safer and more effective approach is the administration of $0.9 \% \mathrm{NaCl}$ in a continuous infusion following bolus therapy. $0.9 \% \mathrm{NaCl}$ not only serves as prophylaxis against hyponatremia, but it is superior to
\end{abstract}

\footnotetext{
M. L. Moritz ( $\bowtie)$

Division of Nephrology, Department of Pediatrics, Children's Hospital of Pittsburgh of UPMC,

The University of Pittsburgh School of Medicine,

One Children's Hospital Drive, 4401 Penn Ave,

Pittsburgh, PA 15224, USA

e-mail: moritzml@upmc.edu

J. C. Ayus

Department of Clinical Research, Renal Consultants of Houston,

Houston, TX, USA
}

hypotonic fluids as an extracellular volume expander and corrects the volume deficit more rapidly.

Keywords Encephalopathy · Fluid therapy

Gastroenteritis $\cdot$ Hypernatremia $\cdot$ Hyponatremia $\cdot$ Sodium

Gastroenteritis is one of the most common medical conditions seen by pediatricians, accounting for over 150,000 hospitalizations per year or approximately $10 \%$ of all hospital admissions in children $<5$ years of age in the USA [1]. The standard approach to intravenous fluid therapy for these children has been to administer a 20 $40 \mathrm{ml} / \mathrm{kg}$ bolus of $0.9 \%$ sodium chloride $(\mathrm{NaCl})$ followed by a hypotonic solution with a sodium concentration ranging from $0.2-0.45 \% \mathrm{NaCl}$ to replace the remaining deficit plus maintenance if unable to tolerate an oral rehydration solution [2]. We have questioned the safety of using a hypotonic fluid in this approach [3, 4], as there have been reports of death or permanent neurologic impairment from hospital-acquired hyponatremic encephalopathy [5-7]. It is now well established that hypotonic maintenance fluids result in hospital-acquired hyponatremia in children [8-10]. This has been best demonstrated in the post-operative setting where the incidence of hospital-acquired hyponatremia (sodium $<135 \mathrm{mEq} / \mathrm{L}$ ) is $20-30 \%$ [11-15]. Surprisingly, there have been no studies to evaluate the safety of the deficit-plus-maintenance-fluid approach in hospitalized children with gastroenteritis.

In this issue of Pediatric Nephrology, Hanna and Saberi evaluated the incidence of hyponatremia (sodium $<135 \mathrm{mEq} /$ L) in children treated with deficit-plus-maintenance-fluid therapy for gastroenteritis [16]. They found the incidence of hospital-acquired hyponatremia to be $18.5 \%$ for patients presenting with isonatremic dehydration, with an average fall 
in serum sodium of almost $6 \mathrm{mEq} / \mathrm{L}$ in approximately $13 \mathrm{~h}$ in those that developed hyponatremia. The average fall in serum sodium for all patients studied was $1.7 \mathrm{mEq} / \mathrm{L}$. No patients developed hyponatremic encephalopathy. The results of this study confirm that the current approach of using hypotonic fluids following bolus fluid therapy in children with gastroenteritis results in a high incidence of hyponatremia.

The majority of patients with gastroenteritis have isotonic dehydration. In these patients, the volume deficit is primarily extracellular. In the deficit-plus-maintenance approach, part of the extracellular volume deficit is replaced with a fluid bolus, with the remainder being replaced over $24 \mathrm{~h}$ along with the maintenance fluids. The problem with this approach is that when the composition of the maintenance fluid used to calculate the final fluid composition is a hypotonic solution with a sodium concentration of $30 \mathrm{mEq} / \mathrm{L}$, as originally proposed by Holliday and Segar [17], the final sodium composition of the intravenous fluids will always be hypotonic. Hypotonic maintenance fluids are not appropriate for patients with increased arginine vasopressin (AVP) as this will predictably result in hyponatremia due to free water retention [18]. Gastroenterits is a known state of AVP excess [19] due to both hemodynamic stimuli for AVP production from volume depletion and non-hemodynamic stimuli, such as nausea and vomiting. Free water will be retained following the initial fluid bolus until the volume deficit is fully corrected and the hemodynamic stimulus for AVP production abates. A safer and more effective approach in the management of children with gastroenteritis would be to administer a continuous infusion with a sodium concentration of $0.9 \% \mathrm{NaCl}$ following bolus therapy. $0.9 \%$ would not only serve as prophylaxis against hyponatremia, but it is superior to hypotonic fluids as an extracellular volume expander and would correct the volume deficit faster. $0.9 \%$ $\mathrm{NaCl}$ could be discontinued in favor of a hypotonic solution once the patient is deemed to be volume replete, as evidenced by good peripheral perfusion and urine output, and intravenous fluid could be stopped altogether when oral fluids are taken well.

$0.9 \%$ would seem to be the best choice to correct volume depletion and prevent the development of dysnatremia in patients with gastroenteritis, but it is not without risk. Hypernatremia can develop in patients with gastroenteritis treated with $0.9 \% \mathrm{NaCl}$ from either large gastrointestinal free water losses or increased insensible water losses from high fever. These high-risk patients should be closely monitored, and measures to prevent hypernatremia should be taken. $0.9 \% \mathrm{NaCl}$ should only be used until the patient is assessed to be volume replete, at which point hypotonic fluids could be used. Electrolytes should be monitored at least daily in these high-risk patients, and isotonic fluid should be discontinued if the patient is hypernatremic (sodium $>144 \mathrm{mEq} / \mathrm{L}$ ).

\section{References}

1. Chang HG, Glass RI, Smith PF, Cicirello HG, Holman RC, Morse DL (2003) Disease burden and risk factors for hospitalizations associated with rotavirus infection among children in New York State, 1989 through 2000. Pediatr Infect Dis J 22:808-814

2. Friedman AL (2005) Pediatric hydration therapy: Historical review and a new approach. Kidney Int 67:380-388

3. Moritz ML, Ayus JC (2003) Prevention of hospital-acquired hyponatremia: a case for using isotonic saline. Pediatrics 111:227-230

4. Moritz ML, Ayus JC (2005) Hypotonic fluids should not be used in volume-depleted children. Kidney Int 68:409-410

5. Gregorio L, Sutton CL, Lee DA (1997) Central pontine myelinolysis in a previously healthy 4-year-old child with acute rotavirus gastroenteritis. Pediatrics 99:738-743

6. Moritz ML, Ayus JC (2005) Preventing neurological complications from dysnatremias in children. Pediatr Nephrol 20:1687-1700

7. Playfor S (2003) Fatal iatrogenic hyponatraemia. Arch Dis Child 88:646-647

8. Armon K, Riordan A, Playfor S, Millman G, Khader A (2008) Hyponatraemia and hypokalaemia during intravenous fluid administration. Arch Dis Child 93:285-287

9. Hoorn EJ, Geary D, Robb M, Halperin ML, Bohn D (2004) Acute hyponatremia related to intravenous fluid administration in hospitalized children: an observational study. Pediatrics 113:1279-1284

10. Moritz ML, Ayus JC (2009) New aspects in the pathogenesis, prevention, and treatment of hyponatremic encephalopathy in children. Pediatr Nephrol. doi:10.1007/s00467-009-1323-6

11. Au AK, Ray PE, McBryde KD, Newman KD, Weinstein SL, Bell MJ (2008) Incidence of postoperative hyponatremia and complications in critically-ill children treated with hypotonic and normotonic solutions. J Pediatr 152:33-38

12. Eulmesekian PG, Perez A, Minces PG, Bohn D (2010) Hospitalacquired hyponatremia in postoperative pediatric patients: Prospective observational study. Pediatr Crit Care Med. doi:10.1097/ PCC.0b013e3181ce7154

13. Montanana PA, Modesto I Alapont V, Ocon AP, Lopez PO, Lopez Prats JL, Toledo Parreno JD (2008) The use of isotonic fluid as maintenance therapy prevents iatrogenic hyponatremia in pediatrics: a randomized, controlled open study. Pediatr Crit Care Med 9:589-597

14. Neville KA, Sandeman DJ, Rubinstein A, Henry GM, McGlynn M, Walker JL (2010) Prevention of hyponatremia during maintenance intravenous fluid administration: a prospective randomized study of fluid type versus fluid rate. J Pediatr 156:313-319.e2

15. Yung M, Keeley S (2009) Randomised controlled trial of intravenous maintenance fluids. J Paediatr Child Health 45:9-14

16. Hanna M, Saberi MS (2010) Incidence of hyponatremia in children with gastroenteritis treated with hypotonic intravenous fluids. Pediatr Nephrol. doi:10.1007/s00467-009-1428-y

17. Holliday MA, Segar WE (1957) The maintenance need for water in parenteral fluid therapy. Pediatrics 19:823-832

18. Moritz ML, Carlos Ayus J (2007) Hospital-acquired hyponatremiawhy are hypotonic parenteral fluids still being used? Nat Clin Pract Nephrol 3:374-382

19. Neville KA, Verge CF, O'Meara MW, Walker JL (2005) High antidiuretic hormone levels and hyponatremia in children with gastroenteritis. Pediatrics 116:1401-1407 